\title{
Significance of Spinal Cord Swelling in the Prognosis of Acute Cervical Spinal Cord Injury
}

\author{
I. Koyanagi, MD, Y. Iwasaki, MD, T. Isu, MD, M. Akino, MD, H. Abe, \\ MD \\ Department of Neurosurgery, Hokkaido University School of Medicine, Sapporo, \\ Japan.
}

\begin{abstract}
Summary
Seven cases of acute cervical cord injury examined by CT-myelography are reported. Cord swelling was observed in 2 patients who developed complete lesions. Another 5 cases had an incomplete lesions. Spinal cord swelling indicated severe cord damage. External decompression seemed to have little effect on cord swelling. When cord swelling is absent, neurological improvement was expected though the initial neurological state showed severe deficits. A further 4 patients who had an acute cervical cord injury who were treated by myelotomy at the injury site are also reported. Two patients obtained significant improvement in upper limb function. The presence or absence of cord swelling as shown by CT-myelography is important for diagnosing the severity of cord damage. Myelotomy in the immediate postaccident period may relieve the effects of cord swelling.
\end{abstract}

Key words: Cervical cord injury; Spinal cord swelling; CT-myelography; Myelotomy.

CT-myelography using water soluble contrast material has been used to study acute spinal cord injury. CT-myelography can visualise not only bone fragments or protruded disc in the spinal cord, but also the shape of the spinal cord itself. The purpose of this report is to emphasise the significances of the diagnosis of cord swelling in the treatment of acute spinal cord injury.

We studied retrospectively CT-myelographic findings, the initial neurological status and the clinical outcome of patients with acute cervical cord injury in our institute from 1982 to 1984 . Treatment for these patients was external decompression or external immobilisation association with steroids and the administration of hyperosmolarity agents. Since 1985, we have carried out posterior midline myelotomy for patients with cord swelling as an internal 
Table I

\begin{tabular}{|c|c|c|c|c|c|c|}
\hline Case & Age & Sex & Lesion & $\begin{array}{l}\text { Initial } \\
\text { grade }\end{array}$ & $\begin{array}{c}\text { Cord } \\
\text { swelling }\end{array}$ & Treatment \\
\hline 1 & 40 & $M$ & $\begin{array}{l}\text { C4 anterior dislocation } \\
\text { C5 body fracture }\end{array}$ & A & $(+)$ & Anterior fusion \\
\hline 2 & 18 & $\mathbf{M}$ & C6 body fracture & A & $(+)$ & Anterior fusion \\
\hline 3 & 46 & $\mathbf{M}$ & C7 body fracture & A & $(+)$ & Halo vest \\
\hline 4 & 20 & $\mathbf{M}$ & $\begin{array}{l}\text { C } 6 \text { body fracture and } \\
\text { lamina fracture }\end{array}$ & B & $(-)$ & Halo vest \\
\hline 5 & 51 & $\mathbf{M}$ & $\mathrm{C} 7$ anterior dislocation & $\mathrm{C}$ & $(-)$ & $\begin{array}{l}\text { Laminectomy and anterior } \\
\text { fusion }\end{array}$ \\
\hline 6 & 37 & $\mathbf{M}$ & $\begin{array}{l}\mathrm{C} 3 / 4, \mathrm{C} 5 / 6 \text { disc } \\
\text { dislocation }\end{array}$ & $\mathrm{C}$ & $(-)$ & Anterior fusion \\
\hline 7 & 73 & $\mathbf{M}$ & No bony injury & $\mathrm{C}$ & $(-)$ & Halo vest \\
\hline
\end{tabular}

^ neurological grade by Frankel: $\mathrm{A}=$ complete, $\mathrm{B}=$ sensory only, $\mathrm{C}=$ motor useless, $\mathrm{D}=$ motor useful, $\mathrm{E}=$ recovery

decompression, because external decompression did not have sufficient effect.

The retrospective studies about CT-myelographic findings, and the results of myelotomy on the acute cervical cord injury are reported here.

\section{Materials and methods}

Seven patients with acute cervical cord injury were examined with CT-myelography within 1 week after trauma and were reviewed. They were all males, aged 18 to 73 years (mean 40.7 years). The initial neurological state of each patient was estimated by the method of Frankel (1969), which defines 5 grades $\mathrm{A}$ to $\mathrm{E}$ according to motor and sensory deficits. Three cases were graded $\mathrm{A}, 1$ case $B$, and 3 cases $C$ (Table I).

CT-myelography was performed after conventional myelography via a C1-2 lateral puncture. Two patients were examined within 24 hours of injury and the others were examined 2 to 6 days after injury. Increase in A-P diameter of the cord or disappearance of the anterior and posterior subarachnoid space were considered to demonstrate cord swelling. In the patient with a complete block, cord swelling was estimated at the level just above the block.

Steroids and other hyperosmolarity agents were administered to all of the patients. Three underwent anterior fusion, and 1 patient had a laminectomy followed an an anterior fusion. External immobilisation with a Halo vest was applied to the other 3 patients.

\section{Results}

Two patients were neurologically grade $\mathrm{A}$ and showed marked cord swelling. Complete block of subarachnoid space associated with cervical dislocation and observed in 1 grade A patient and 1 grade $\mathrm{C}$ patient (Table I).

Figure 1 summarises neurological changes in each patient. Two grade $\mathbf{A}$ patients with cord swelling (Cases 1 and 2) showed no improvement. On the contrary, 4 of the other 5 patients did improve neurologically. One grade $\mathrm{C}$ patient remained at grade $\mathrm{C}$. 


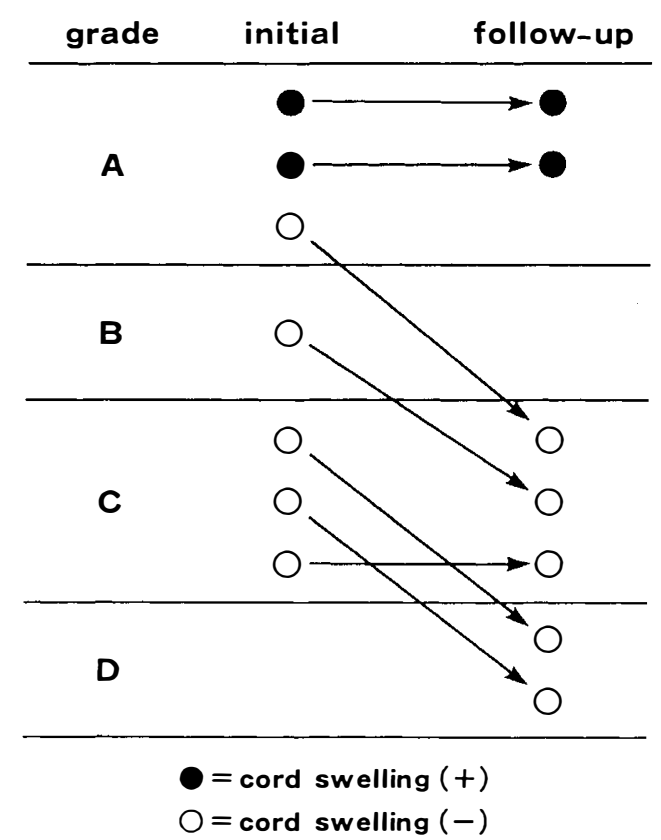

Figure 1 Neurological changes found. Closed circles indicate those with cord swelling. Open circles indicate those who showed no cord swelling.

\section{Illustrative cases}

Case 2.

An 18-year-old boy was involved in a traffic accident while driving a car and became quadriplegic. He was treated at another hospital and was admitted to our hospital 5 days afer the accident.

Neurological state: Weakness of triceps and hand muscles bilaterally; complete paralysis of the legs; paradoxical respiration, and sensory loss below C8 level. The initial grade was $\mathbf{A}$.

Radiological findings: Neck roentgenograms showed a compressed fracture of C6 body. CT-myelography revealed cord swelling from C4 to C6 level (Fig. 2).

Clinical course: An anterior fusion was performed after skull traction was applied. Neurological improvement was not obtained.

\section{Case 5.}

A 51-year-old man fell into a manhole and was admitted to our hospital the following day.

Neurological state: Weakness of graspiing power and paraparesis. Sensory disturbance below $\mathrm{T} 5$ level. The initial grade was $\mathrm{C}$.

Radiological findings: Neck roentgenograms showed an anterior dislocation of C7. Skull traction was performed immediately. Conventional myelography via C1-2 lateral puncture on the sixth day demonstrated complete block of subarachnoid space at C7/T1 level (Fig. 3A). CT-myelography did not show cord swelling above the level of block (Fig. 3B).

Clinical course: Laminectomy and posterior reduction followed by anterior fusion were performed. He showed gradual improvement, and his neurological grade became D. 

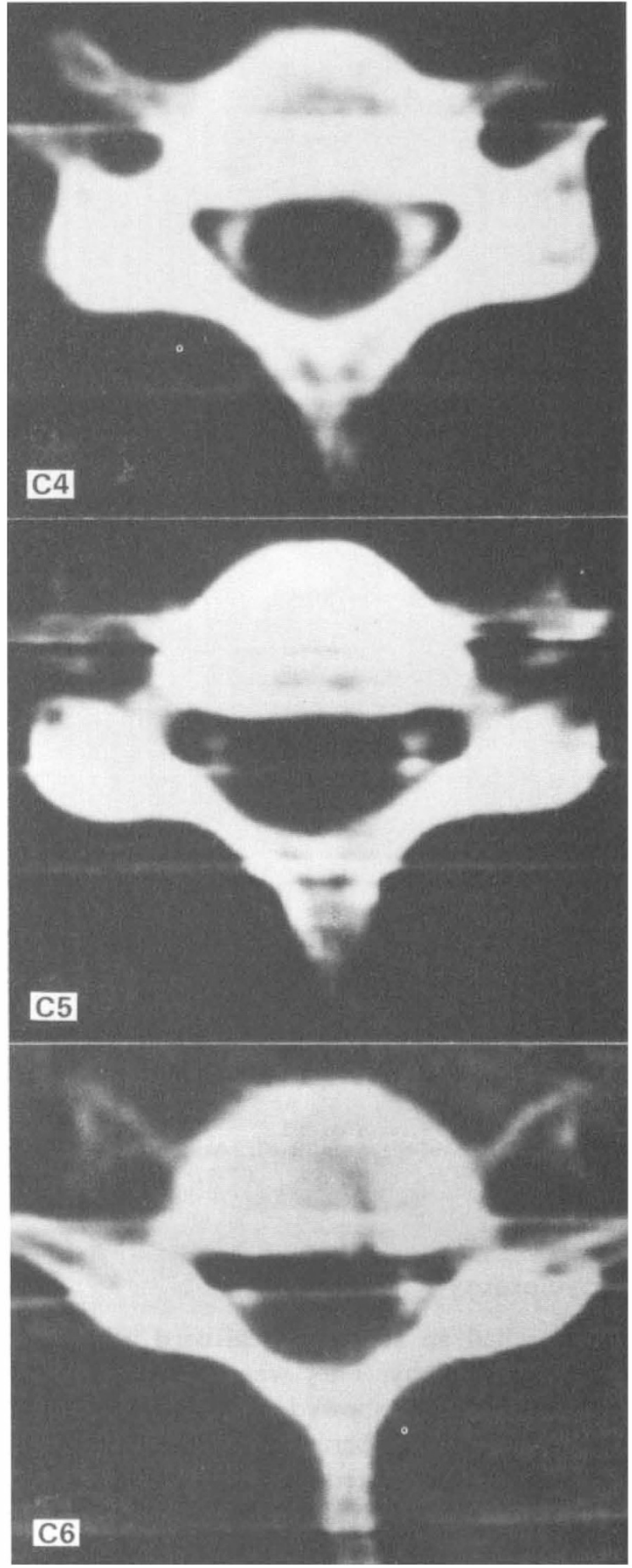

Figure 2 Case 2. CT-myelography reveals the cord swelling from C4-C6. 


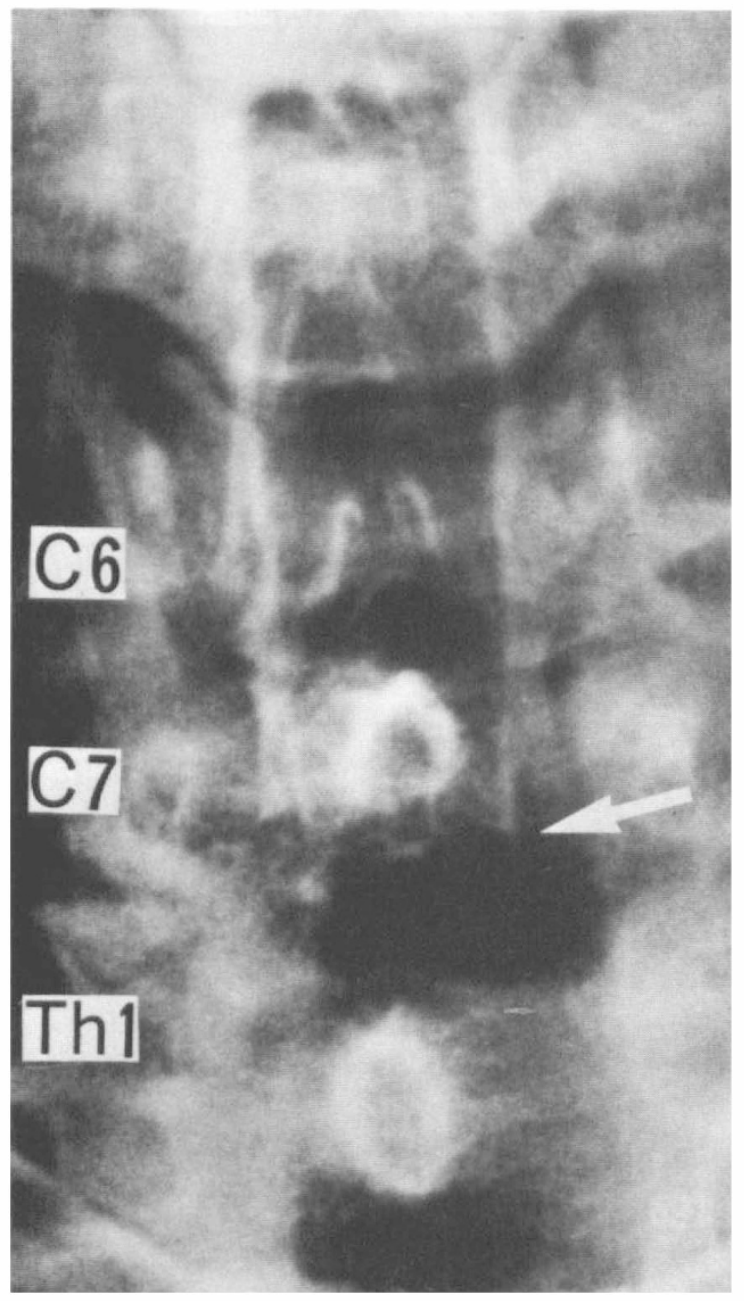

Figure 3A Myelography of case 5 via C1-2 lateral puncture. Frontal view shows a complete block of the subarachnoid space at the level of C7-T1.

\section{Case report of myelotomy}

Since 1985, 4 patients had an acute cervical cord injury with cord swelling and were treated by a myelotomy. They were 3 men and 1 woman, aged 35 to 48 years (mean 39.8 years). Each showed complete motor and sensory deficits. Posterior midline myelotomy was performed at the site of cord swelling after the application of skull traction, or reduction of the dislocation, associated with administration of steroids and hyperosmolarity agents. The interval from injury to myelotomy was 5 hours, 12 hours, 18 hours, and 21 hours (Table II). The extent of the myelotomy was 2 to 3 levels. Soft, haemorrhagic necrotic tissue was found in the swollen cord, which was gently irrigated and removed by the operation. There was no neurological deterioration following the myelotomy. 


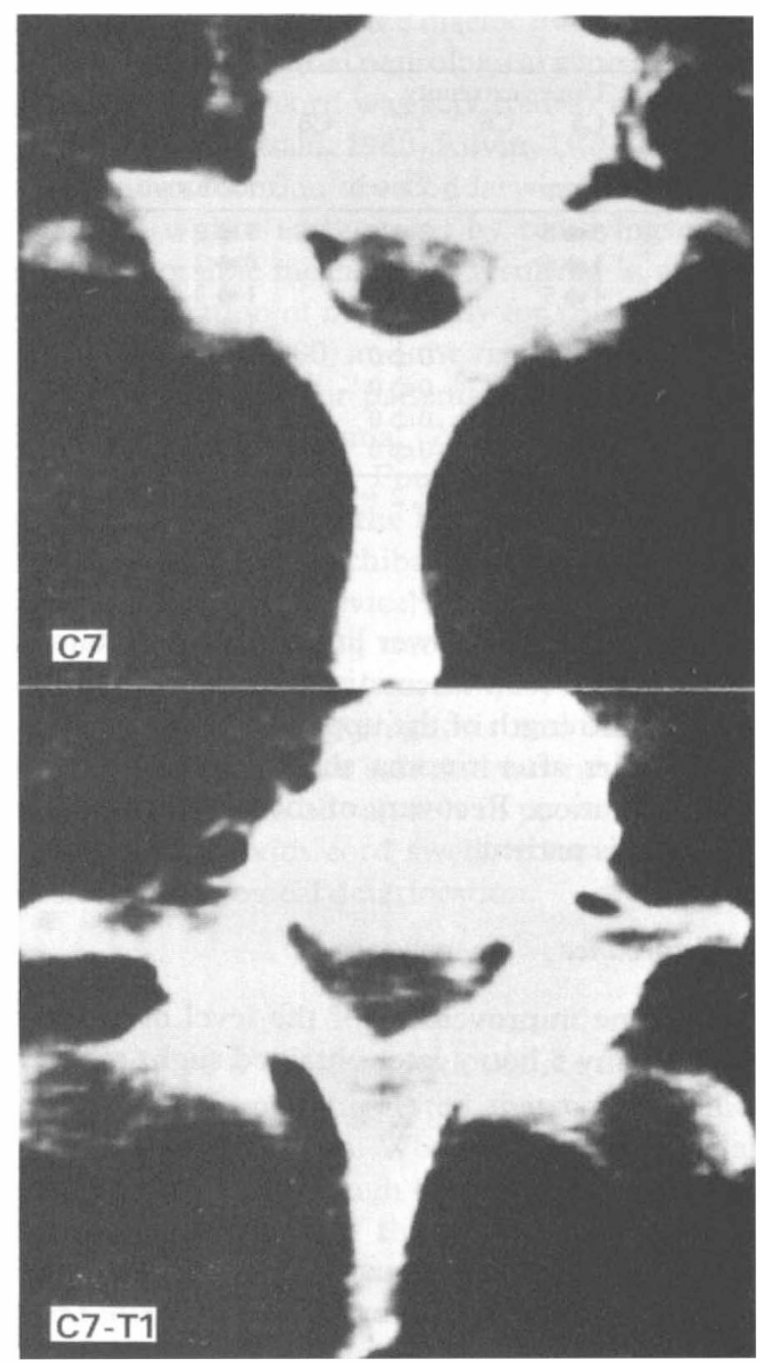

3B CT-myelography of case 5 shows no cord swelling at the level of C7 and complete block of the subarachnoid space at the level of C7-T1.

Table II

\begin{tabular}{cccccc}
\hline Case & Age & Sex & $\begin{array}{c}\text { Time to } \\
\text { admission } \\
\text { (hours) }\end{array}$ & $\begin{array}{c}\text { Initial } \\
\text { Level of } \\
\text { cord injury }\end{array}$ & $\begin{array}{c}\text { grade } \\
\text { (Frankel) }\end{array}$ \\
\hline 1 & 35 & M & 0.5 & C6 & A \\
2 & 37 & F & 3.5 & C7 & A \\
3 & 48 & M & 7.5 & C5 & A \\
4 & 39 & M & 1 & C5 & A \\
\hline
\end{tabular}


Table III

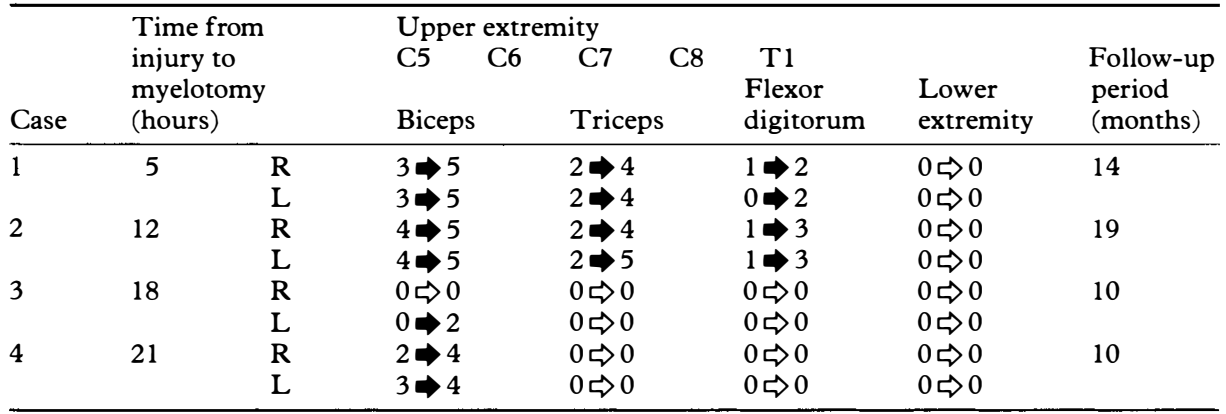

Muscle power: $5=$ normal, $4=$ good, $3=$ fair, $2=$ poor, $1=$ trace, $0=$ none

Change of motor function (Table III)

Recovery of motor function of the lower limbs was not obtained, but 2 patients who underwent myelotomy soon after injury ( 5 hours, and 12 hours) showed good recovery of muscle strength of the upper limbs. One patient whose myelotomy took place 18 hours after trauma showed progressive neurological deterioration until the operation. Recovery of motor function of the upper limbs was not satisfactory in this patient.

\section{Change of sensory disturbance}

All patients showed some improvement of the level of analgesia. One patient who underwent myelotomy 5 hours later obtained slight recovery of light touch in one leg.

\section{Discussion}

Early pathological changes of the traumatised spinal cord were reported to be small haemorrhages in the central grey matter (Allen, 1914; Ducker, 1971). By 4 to 6 hours haemorrhage in the grey matter increased and oedema of the white matter was becoming extreme (Allen, 1914). As the injured force was increased, such a pathological change became severe (Ducker, 1971). From these experimental works, cord swelling seemed to reflect the degree of cord damage in the acute state, and would be an important finding to determine the prognosis.

In clinical cases, cord swelling was diagnosed by myelography or observation during surgery. Recent advances in water soluble contrast materials and CTscan enables us to inspect the cord swelling in the transverse plane. In our retrospective study on acute cervical cord injury patients examined by CTmyelography, 2 patients (cases 1 and 2) had cord swelling. Their initial and follow-up neurological grade was A, suggesting complete cord damage. Another 5 patients who had no evidence of cord swelling were in the grade $\mathrm{C}$ (Cases 3, 4 and 7); and $\mathrm{D}$ (Cases 5 and 6 ).

These results suggested that cord swelling indicated severe cord damage. External decompression had little effect in such patients. On the contrary, if cord swelling is not apparent, there might be a possibility of improvement after external 
decompression such as reduction of the disclocated spine, or anterior or posterior decompression, although the initial neurological state indicates a complete lesion.

Myelotomy of the injured cord was reported to be effective in experimental studies (Campbell, 1973; Iwasaki, 1980; Rilvin, 1979; Wagner, 1978). Reduction of tissue pressure and prevention of secondary irreversible changes in the spinal cord which occurred within early stage, by removing extravasated blood and necrotic tissue were possible mechanisms resulting in a beneficial effect (Allen, 1914). Our clinical indication of myelotomy for spinal cord injury was based on experimental data (Iwasaki, 1980) and the retrospective clinical study described above. We restrict myelotomy for patients who satisfy 3 conditions: (1) acute, at least within 24 hours after trauma, (2) those with a neurologically complete lesion (Frankel), (3) cord swelling. Four of our patients who had a myelotomy did not recover motor function in the legs, but 2 obtained significant improvement in upper limb function. Tachibana et al., (Tachibana, 1984) reported 6 cases of complete transverse cervical cord injury treated by myelotomy; 2 patients recovered function of long tracts, and all had reduction of the level of the neurological deficit. In cervical cord injury, any improvement of the level of deficit is important regarding prognosis and ADL. Myelotomy under the microscope by a skilful surgeon is safe and has no adverse effect on the spinal cord. Myelotomy is thought to be valuable in preventing secondary neurological aggravation because those with cord swelling have a poor prognosis and may develop progressive neurological deterioration.

\section{Conclusions}

A retrospective study of 4 patients with an acute cervical cord injury were examined by CT-myelography suggested that cord swelling indicated severe cord damage and a poor prognosis. When cord swelling is absent, neurological improvement is expected even though the initial neurological state shows severe deficits. Evaluation of the shape of the traumatised spinal cord by CT-myelography is important for the diagnosis the degree of cord damage. Myelotomy soon after trauma may be effective in alleviating the effects of cord swelling.

\section{References}

Allen AR 1914 Remarks on the histopathological changes in the spinal cord due to impact. fournal of Nervous Mental Disorders 41: 141-147.

Campbell JB, DeCrescico V, Tomasula BS et al. Experimental treatment of spinal cord contusion in the cat. Surgical Neurology 1:102-106

Ducker TB, KIndT GW, Kempe LG 1971 Pathological findings in acute experimental spinal cord trauma. Fournal of Neurosurgery 35:700-708.

FRANKel HL, HANCOCK DO, Hyslop G, et al. The value of postural reduction in the initial management of closed injuries of the spine with paraplegia and tetraplegia. Paraplegia 73:179192.

IWASAKI Y, ITOU T, IsU T, et al. 1980 Effect of longitudinal myelotomy on experimental spinal cord surgery. Neurological Surgery 8:65-72.

RIVLIN AS, TATOR CH 1979 Effect of vasodilators and myelotomy on recovery after acute spinal cord injury in rats. Fournal of Neurosurgery 50:349-352.

TAChibana S, OKada K, OHWAda T, et al. 1984 Posterior logitudinal myelotomy as a surgical treatment of acute cervical cord injury. Neurological Surery 12:183-188.

Wagner FC, VanGilder JC, Dohrmann GJ 1978 Pathological changes from acute to chronic in experimental spinal cord trauma. Fournal of Neurosurgery 48:92-98. 